\title{
The enhanced remediation of DDT contaminated soil by
}

\section{Surfactant-stabilized foam flushing}

\author{
Xingwei Wang ${ }^{1, a}$, Jiajun Chen ${ }^{1, b}$, Yunsong Liu $^{1, c}$, Meng Wei ${ }^{1, d}$, Lanxiang Shi ${ }^{1, e}$ \\ ${ }^{1}$ Key Laboratory for Water and Sediment Sciences of Ministry of Education, School of Environment, \\ Beijing Normal University, Beijing 100875, China. \\ awangxingwei0812@gmail.com, bjeffchen@bnu.edu.cn, liuyunsong@mail.bnu.edu.cn,

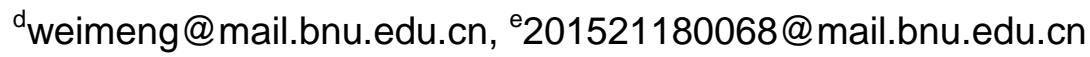

Keywords: DDT, Soil remediation, Foam flushing, Surfactant, Removal efficiency

Abstract: In this study, two flushing modes including surfactant solution flushing and surfactant-stabilized foam flushing were conducted for in-situ soil remediation to remove DDT contaminants. The results showed that surfactant-stabilized foam flushing could significantly enhance the overall sweep efficiency, and then improved the DDT contaminants removal efficiency in heterogeneous soil. Compared with solution flushing, foam flushing was more suitable for remediate heterogeneous soil due to its intrinsic permeability characteristics. The obtained results would provide useful information and technical support for DDT soil remediation.

\section{Introduction}

DDT is a chlorinated pesticide which was once used widely for control of agricultural pests and disease vectors [1-2]. Although its usage has been banned or severely restricted for the past few decades, DDT and its metabolites are still detected in water, sediment and animals due to its persistence [3-6]. Since DDT tends to remain adsorbed to soil particles in an immobile manner, and its resistance to biodegradation results in persistence in the soil environment for long periods of time, which has posed a great threat to human health [7]. Therefore, it is necessary to identify and use techniques to remediate DDT-contaminated soil to a satisfactory level in China.

Among various remediation technologies, surfactant-stabilized foam flushing is an innovative technology for in-situ soil remediation and has been developed as one of promising technologies owing to its high macroscopic sweep efficiency and contaminant removal efficiency [8-12]. The inherent resistance characteristic of foam flushing provides greater flow resistance in high-permeability region than in low-permeability region, which was conducive to complete contact between the injected surfactant and the contaminants in heterogeneous soil, and finally improves contaminants removal efficiency [13]. Due to the above advantages, foam flushing technology has been widely used to remove pollutants from contaminated soils, such as polynuclear aromatic hydrocarbons (PAHs), polychlorinated biphenyls (PCBs), pentachlorophenol (PCP), and heavy metal.

The objective of this study is to use surfactant-stabilized foam flushing technology to remediate DDT contaminated soil. In order to demonstrate its enhanced removal effect, the traditional surfactant solution flushing experiments will also be carried out comparatively under the same condition. The sweep efficiency and contaminants removal efficiency are compared. The obtained results will provide useful information and technical support for DDT soil remediation. 


\section{Materials and methods}

Materials The soil used in the column experiments were collected from the surface soil in Beijing City, China, and the particle size distribution data were analyzed by laser method (as shown in Fig. 1). The porosity of soil was $41.8 \%$. The preliminary experiments indicated that the soil sample can be used for foam-flushing technique. P,P'-DDT as the representative DDT was selected in this study. The foaming agent was chosen sodium dodecyl sulfate (SDS) due to its good foaminess and widely used. The critical micelle concentration (CMC) of SDS was determined as $915.13 \mathrm{mg} / \mathrm{L}$. The preliminary experiments showed surfactant concentration of $0.5 \%$ by weight had good foamability and was chosen in this study.

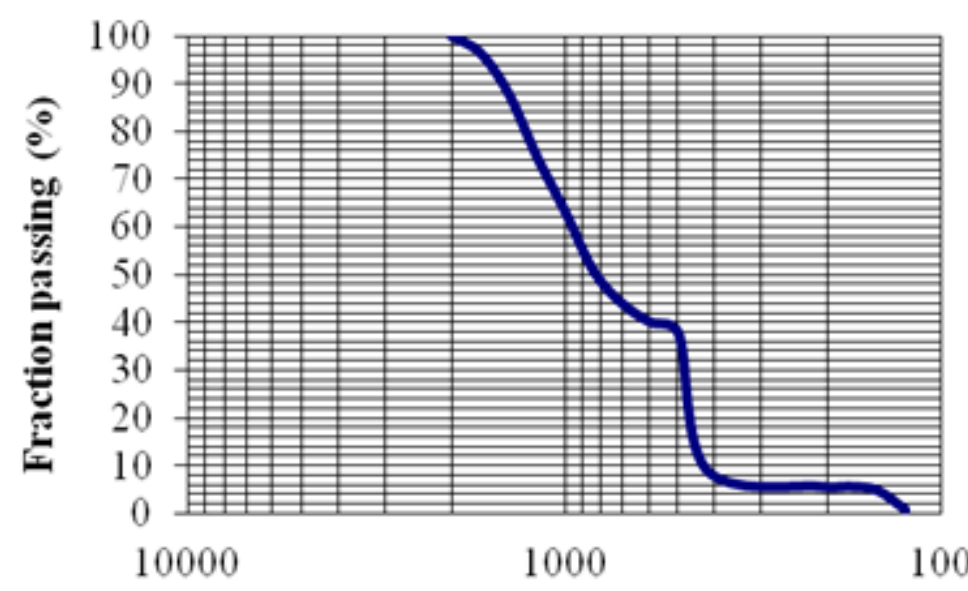

Grain size $(\mu \mathrm{m})$

Fig. 1 Particle size distribution of the experimental soil

DDT contaminated soil preparation Soil $(800 \mathrm{~g})$ was transferred into a polyvinylidene fluoride tray in a fume hood. Using an air-operated atomizer, the DDT solution in hexane (20 $\mathrm{mg}$ of DDT in $30 \mathrm{~mL}$ hexane) was sprayed slowly on to the soil completely. During spraying, the soil was mixed thoroughly with a glass spoon. Following the addition of DDT solution to the soil, the DDT-spiked soil (nominally $25 \mathrm{mg} / \mathrm{kg}$ ) was then allowed to dry in the fume hood for $24 \mathrm{~h}$ to evaporate the entire solvent and ensure that the DDT adhered to the soil.

Surfactant-stabilized foam flushing for DDT contaminated soil remediation The sketch of experimental apparatus for investigating foam flow resistance is shown in Fig. 2. Foam was generated when the surfactant solutions and nitrogen passed simultaneously through self-made Foam Generator Apparatus (FGA). The gas and surfactant flow rates were manipulated by flow meter so that a predetermined foam quality could be obtained. The soil column was $15 \mathrm{~cm}$ long with $5 \mathrm{~cm}$ in inner diameter. The packed soil column had a total pore volume (PV) of $123.0 \mathrm{~cm}^{3}$. The two-dimensional box for sweep efficiency experiment was shown in Fig.3. The system was packed with experimental soil. When fully packed, a leak test was conducted for each system to confirm the seal before further testing steps. Each experimental test was carried out for three times, and the average value was utilized for the final analysis. 


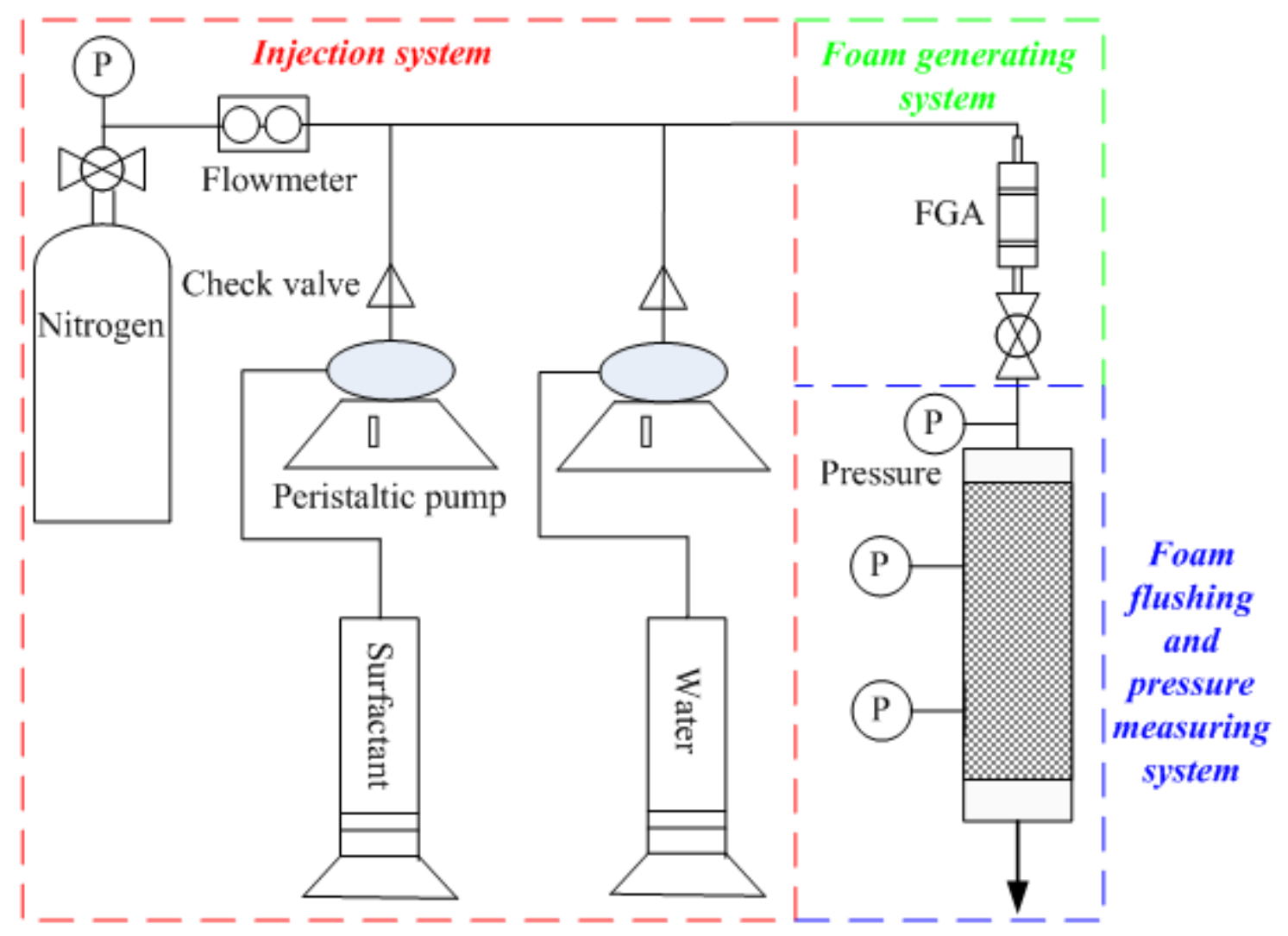

Fig. 2 The schematic diagram of the foam flow experiment

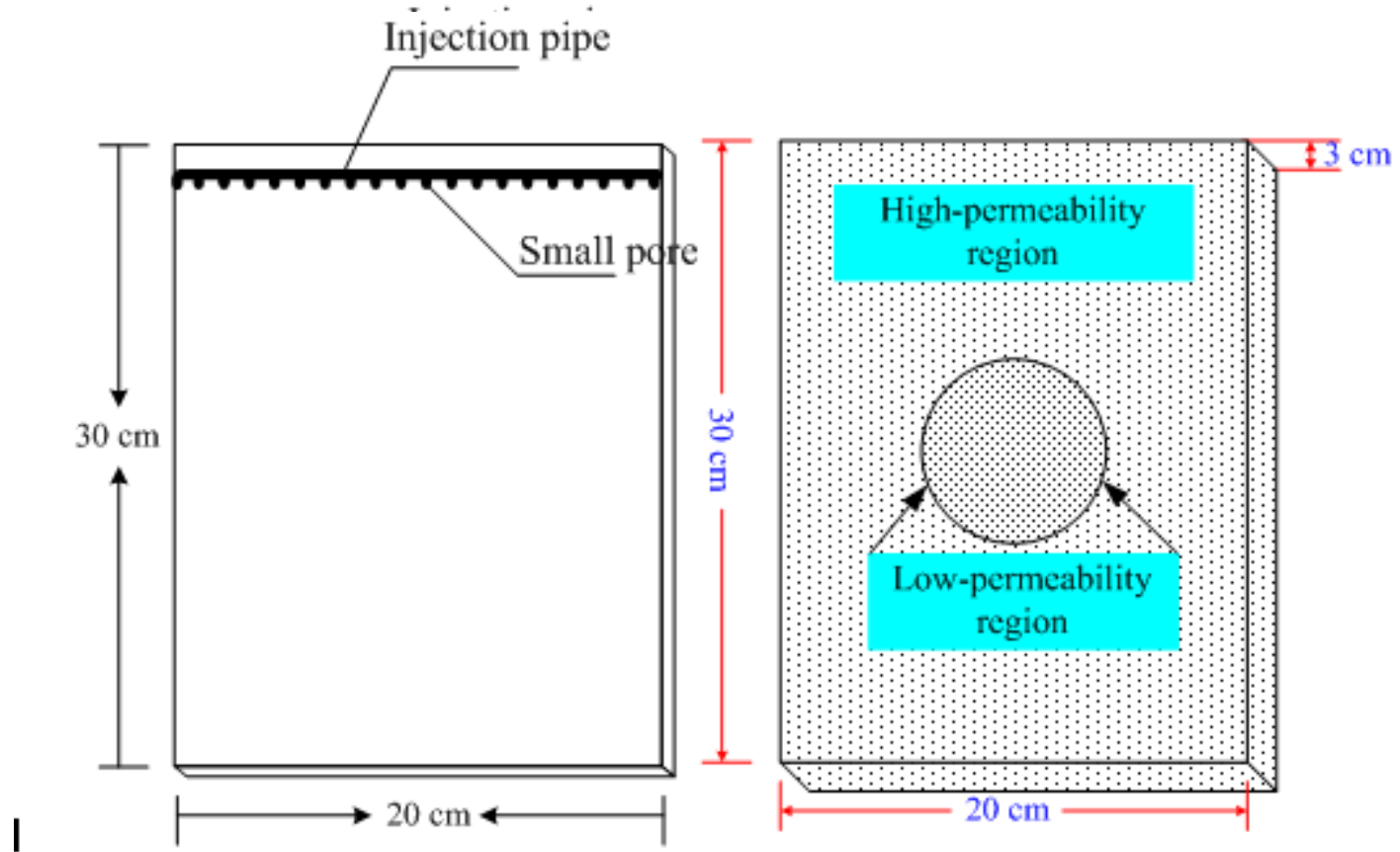

Fig. 3 The two-dimension box for sweep efficiency experiment

Results and discussion

The enhanced sweep efficiency of foam flushing Fig. 4 displays the sweep efficiency by surfactant solution flushing and foam flushing. At the initial $0.5 \mathrm{PV}$, the migration speed of wetting front on the sides of two-dimension box was higher than the middle for both two flushing modes, especially for solution flushing. This was caused by boundary effect. Since foam had plugging effect for large pores due to its intrinsic permeability characteristics, which could reduce boundary 
effect to some degree. As the flushing process continuing to $1.0 \mathrm{PV}$, a significant different phenomenon was appeared for two flushing modes. In detail, the wetting front have already transited the low-permeability region with roundabout flow for solution flushing. The reason was that solution flushing was mainly controlled by gravity, and would flow into high-permeability region preferentially. While foam flushing was controlled by injection pressure, and would transport in heterogeneous media as piston flow, which could guarantee the wetting front migration in a continuous way. When flushing to $1.5 \mathrm{PV}$, the wetting front has already passed the low-permeability region completely for foam flushing, although the migration speed in low-permeability region was lower than that in high-permeability region. While for solution flushing, the low-permeability region was gradually infiltrated by capillary force. As flushing to 2.0 $\mathrm{PV}$, the whole box has been permeated for the two flushing modes.

Although the low-permeability region was also infiltrated by capillary force for solution flushing, its migration speed was extremely low, and it was difficult to remove the DDT contaminants. While the wetting front for foam flushing transported in a continuous way, which avoided roundabout flow, significantly enhancing the sweep efficiency in low-permeability region, and finally improving the DDT removal efficiency. This had important implications for the actual soil remediation engineering. Since contaminants usually accumulated in low-permeability region due to its smaller particle size, high specific area and water content. Foam flushing can enhance the overall sweep efficiency in restoration area, and thus can achieve a relative ideal contaminant removal efficiency compared with solution flushing.

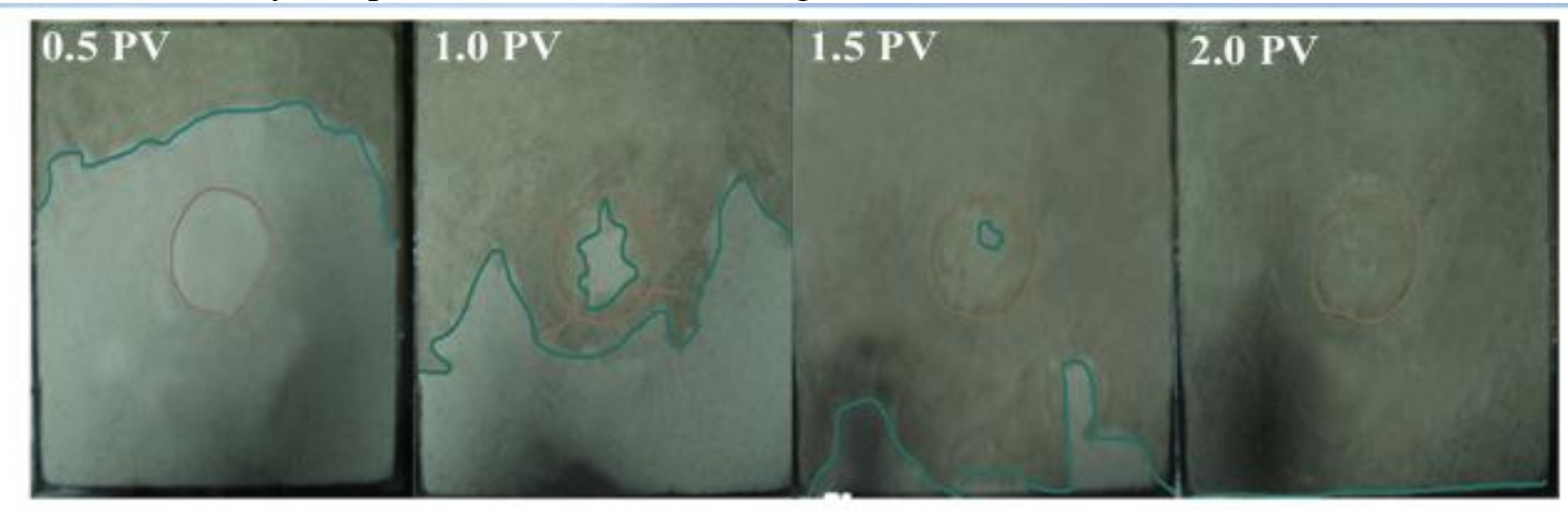

(a)

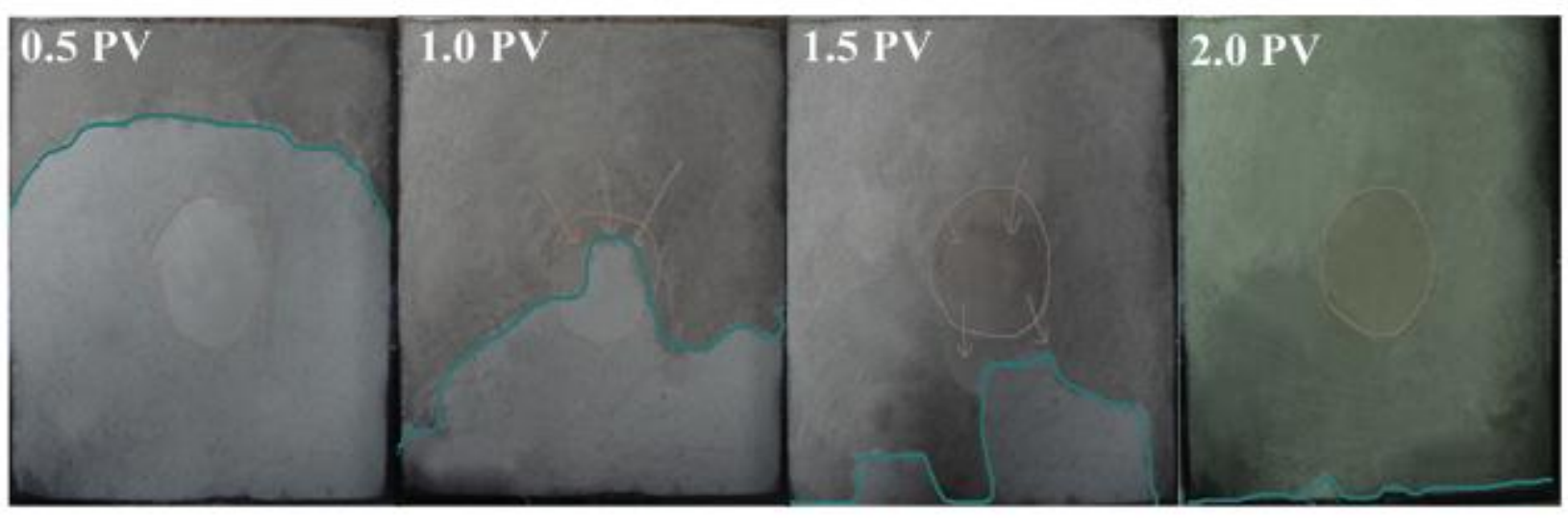

(b)

Fig. 4 The sweep efficincy by (a) solution flushing (b) foam flushing 
The enhanced removal efficiency of foam flushing Fig. 5 shows the effluent DDT concentration and cumulative removal efficiency by surfactant solution flushing and foam flushing. It indicated that DDT removal efficiency was significantly improved due to foam existing. For example, the total removal efficiency of DDT was $19.55 \%, 30.13 \%$ when the flushing process was conducted at 19.92, 19.98 PV for solution flushing, foam flushing, respectively. Compared with surfactant solution flushing, the total removal efficiency was increased by $10.58 \%$ with foam flushing, it also saves 0.06 PV surfactant usage.

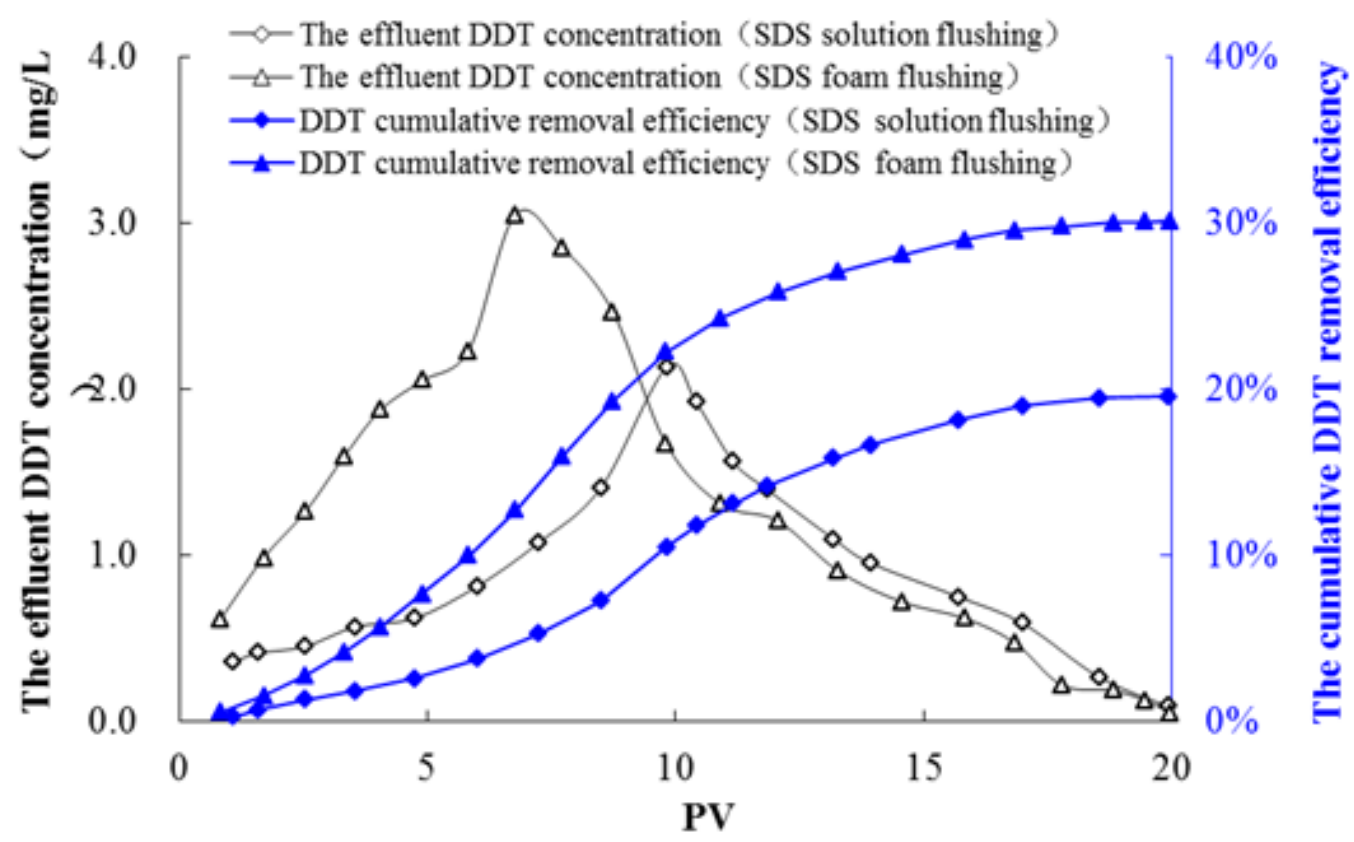

Fig. 5 The effluent DDT concentration and cumulative removal efficiency by two flushing modes

Whether for solution flushing or foam flushing, the maximum effluent DDT concentration was achieved before the flushing process was conducted at $10 \mathrm{PV}$. The effluent DDT concentration was increasing with the flushing PV increasing before the maximum effluent DDT concentration reached, and then it was decreasing with flushing PV increasing for both solution flushing and foam flushing. The experiment results confirmed that the maximum effluent DDT concentration was influenced by various factors, such as surfactant type and concentration, contaminant concentration and soil characteristics and so on. It also indicated that the effluent DDT concentration with foam flushing was higher than that with solution flushing at initial flushing stage, and attained the maximum with less PV flushing. For example, the maximum effluent DDT concentration was achieved at 9.83 PV for solution flushing, 6.77 for foam flushing. While after the maximum effluent DDT concentration achieved, it was falling fast, even lower than that with solution flushing. The reason was due to fact that the preferential flow would formed by solution flushing at initial flushing stage, which need more PV flushing before entering into other flow pathway. While for foam flushing, the maximum effluent DDT concentration would appear when the maximum sweep efficiency was achieved. Since the solubility of DDT by surfactant foam was lower than that by solution, which was also the reason that the effluent DDT concentration was lower than that with solution flushing at final flushing stage. 


\section{Summary}

Surfactant-stabilized foam existing provided greater plugging in high-permeability region than in low-permeability region, which diverted foam flow from high-permeability region to low-permeability region. This was conducive to the complete contact between the injected surfactant and the contaminants in heterogeneous soil, and finally improves contaminants removal efficiency. The experiment results showed that the total DDT removal efficiencies were $19.55 \%$, $30.13 \%$ for solution flushing, foam flushing at approximately flushing $20 \mathrm{PV}$, respectively. Compared with solution flushing, foam flushing was more suitable for remediate heterogeneous soil due to its intrinsic permeability characteristics. The obtained results would provide useful information and technical support for DDT soil remediation.

\section{Acknowledgments}

This work was supported by the National Natural Science Foundation of China (No. 41272248) and National Science and Technology Support Program (No. 2012BAJ21B03-01).

\section{References}

[1] Singh SP, Bose P, Guha S, Gurjar SK, Bhalekar S (2013): Impact of addition of amendments on the degradation of DDT and its residues partitioned on soil. Chemosphere 92, 811-820

[2] Younas A, Hilber I, Rehman S, Khwaja M, Bucheli T (2013): Former DDT factory in Pakistan revisited for remediation: severe DDT concentrations in soils and plants from within the area. Environ Sci Pollut Res 20, 1966-1976

[3] Cao X, Han H, Yang G, Gong X, Jing J (2011): The sorption behavior of DDT onto sediment in the presence of surfactant cetyltrimethylammonium bromide. Marine Pollution Bulletin 62, 2370-2376

[4] Hu W, Lu Y, Wang T, Luo W, Zhang X, Geng J, Wang G, Shi Y, Jiao W, Chen C (2010): Factors affecting $\mathrm{HCH}$ and DDT in soils around watersheds of Beijing reservoirs, China. Environ Geochem Health 32, 85-94

[5] Timilsina GR, Kurdgelashvili L, Narbel PA (2012): Solar energy: Markets, economics and policies. Renewable and Sustainable Energy Reviews 16, 449-465

[6] Yang L, Xia X, Liu S, Bu Q (2010): Distribution and sources of DDTs in urban soils with six types of land use in Beijing, China. Journal of hazardous materials 174, 100-107

[7] Albrecht J (2007): The future role of photovoltaics: A learning curve versus portfolio perspective. Energy Policy 35, 2296-2304

[8] Apaydin OG, Kovscek AR (2001) Surfactant concentration and end effects on foam flow in porous media. Transport in Porous Media 43:511-536.

[9] Roostapour A, Lee G, Zhong L, Kam SI (2014) Model fit to experimental data for foam-assisted deep vadose zone remediation. Journal of hazardous materials 264:460-473.

[10] Shen X, Zhao L, Ding Y, Liu B, Zeng H, Zhong L, Li X (2011) Foam, a promising vehicle to deliver nanoparticles for vadose zone remediation. Journal of hazardous materials 186:1773-80.

[11] Wang H, Chen J (2013) A study on the permeability and flow behavior of surfactant foam in unconsolidated media. Environmental Earth Sciences 68:567-576.

[12] Wang S, Mulligan C (2004a) Rhamnolipid Foam Enhanced Remediation of Cadmium and 
Nickel Contaminated Soil. Water, Air, \& Soil Pollution 157:315-330.

[13 ]Pang Z-X (2010) The Blocking Ability and Flowing Characteristics of Steady Foams in Porous Media. Transport in Porous Media 85:299-316. 